\title{
An Analysis of the Evolution and Inheritance of the Yingjing Sand Ware
}

\author{
Ying Wang ${ }^{1, *}$ Sihan Zhang ${ }^{2}$ Guoqing $\mathrm{Fu}^{1}$ Shuping $\mathrm{Fu}^{1}$ Chuyu Lu${ }^{1}$ Qifan Deng ${ }^{1}$ Sujia \\ Shen ${ }^{1}$
}

${ }^{1}$ College of Humanities, Sichuan Agricultural University, Ya'an, Sichuan 625000, China

${ }^{2}$ School of Arts and Media, Sichuan Agricultural University, Ya'an, Sichuan 625000, China

*Corresponding author. Email: wangying980418@gmail.com

\begin{abstract}
Yingjing sand ware is a handicraft product of the Han nationality, as well as a product against the background of intangible cultural heritage. Its unique features embody a strong culture complex and artistic characteristics. Through literature research, field investigation, this paper analyses the exterior and partial decoration of Yingjing sand ware and combs the structure and size of traditional sand ware, and factors affecting modern black sand products. After understanding the rich history of the Yingjing sand ware, the authors expect that the proposed measures can provide some inspiration and reference for its protection and inheritance.
\end{abstract}

\section{Keywords: intangible cultural heritage, shape evolution, protection and inheritance}

\section{INTRODUCTION}

Sand ware, which is a kind of product between pottery and porcelain, is also common in China. Generally, it is made of clay which is associated with coal. One such type is the Yingjing sand ware, famous for its primitive simplicity of "natural beauty", which has very attractive glazing color after accidental coloring. Its production technique was listed in the second batch of national intangible cultural heritage in 2008, and it is renowned for the good reputation of "The east has purple sands in Yixing and the west has black sands in Yingjing". The concept of "intangible cultural heritage" is not an empty talk. It contains the civilization of the Chinese nation for 5,000 years and the accumulated wisdom of many generations of Chinese people. The heritages come from the simple life and return to life and are deeply rooted in the heart of each inheritor and guardian of brilliant traditional Chinese culture.

\section{CATEGORY OF YINGJING SAND WARE}

As is well known, the Yingjing sand wares are usually divided into two types. The first type is traditional sand wares, mainly including earthen pot and earthen jar, which are generally used to cook. Although

\footnotetext{
*Fund: This paper is supported by the innovation training program of Sichuan Agricultural University: Exploration of the Creative Protection and Development Mode of Intangible Cultural Heritage - a Case Study of Yingjing Sand Ware (Project No.: 201910626058; Advisor: Dou Cunfang).
}

they don't look elegant enough, even some rough, but from the practical point of view they make very good cooking utensils. The other type is the modern black sand wares, usually some tea set or pottery works. This kind of work is delicate in texture, unique after the kiln, and full of artistic beauty in shape. The ancient Yingjing sand ware firing technique has been completely inherited and retained for the wares are used as cooking utensils, which is the solid choice for cooking vessels. However, modern black sand wares are the product of the integration of traditional handicraft and modern technology under the background of protecting and inheriting intangible cultural heritage.

\section{USE AND CHARACTERISTICS OF TRADITIONAL SAND WARE}

\section{A. Sand pot}

In the selection of traditional sand wares, while "straight" sand jars are usually used in the decocting of Chinese herbal medicine, the sand pots are ok for daily cooking, and some specially-made wares will be used in tea making. Sand jars and sand pots are generally bulky. Since they are mostly made of coarse sand, the surface is rough. How are the techniques passed on? It has generally been inherited through the most primitive generation-to-generation and hands-on teaching.

The different demands of the populace for cooking could lead to a shift in the shape of the sand pot, and the diet and physiological demands of the local people may 
also be the reason for the evolution of the device. Sand pots generally have large volume, rough skin and single decoration. Most of them have up-down structure, composed of sand pot cover with handle and porosity and pot body from top to bottom. The body of the pot is round and less decorated. The lifting ears and ring ears are mostly located in the connection of the upper and lower parts to assist people to move the sand pot [1]. Different sand pots are chosen according to different ways of using and varied cooking methods ("Table I").

TABLE I. SHAPE AND SIZE OF COMMON SAND POT

\begin{tabular}{|c|c|c|c|c|c|}
\hline Category & Name & $\begin{array}{c}\text { Caliber } \\
\text { (unit: } \mathbf{m m} \text { ) }\end{array}$ & $\begin{array}{l}\text { bottom diameter } \\
\quad \text { (unit: } \mathbf{m m} \text { ) }\end{array}$ & $\begin{array}{c}\text { Hight } \\
\text { (unit: } \mathbf{m m} \text { ) }\end{array}$ & $\begin{array}{c}\text { volume } \\
\text { (unit: litre) }\end{array}$ \\
\hline \multirow{3}{*}{ Stewing sand pot } & Sand pot with lifting ears a & \multirow{3}{*}{$180-350$} & \multirow{3}{*}{$130-170$} & \multirow{3}{*}{$160-380$} & \multirow{3}{*}{$3-25$} \\
\hline & Sand pot with ring ears & & & & \\
\hline & Barrel sand pot with lifting ears & & & & \\
\hline Boiling sand pot & Sand pot with lifting ears b & $210-360$ & $130-180$ & $70-160$ & $1.5-9$ \\
\hline
\end{tabular}

\section{B. Earthen jar}

With less cooking methods, sand jars are filled with the depth of ancient firing technique. The volume of the sand jar is generally smaller than that of the sand pot, mostly 3-4 liters ("Table II"). The sand jar has the same rough surface and up-down structure as the sand pot.
The difference is that the body of jar is higher, with a drain nozzle, and it tends to be straight cylindrical with almost no decorative carving. In addition, for the convenience of use, there are even uncovered ones, with the single handle and other accessories more concentrated in the upper part.

TABLE II. SHAPE AND SIZE OF COMMON SAND JAR

\begin{tabular}{|c|c|c|c|c|c|}
\hline \multirow{2}{*}{ Category } & \multicolumn{2}{|c|}{ Structure } & \multirow{2}{*}{$\begin{array}{c}\text { Caliber } \\
\text { (unit: } \mathbf{m m} \text { ) }\end{array}$} & \multirow{2}{*}{$\begin{array}{l}\text { Bottom diameter } \\
\quad \text { (unit: } \mathbf{m m} \text { ) }\end{array}$} & \multirow{2}{*}{$\begin{array}{c}\text { Height } \\
\text { (unit: } \mathbf{m m} \text { ) }\end{array}$} \\
\hline & Body & Accessory & & & \\
\hline \begin{tabular}{|c|} 
Chinese medicine \\
pot for health \\
preservation \\
\end{tabular} & \multirow{4}{*}{$\begin{array}{l}\text { Rim of the } \\
\text { mouth } \\
\text { Neck } \\
\text { Belly } \\
\text { Bottom feet }\end{array}$} & \multirow{4}{*}{$\begin{array}{c}\text { Cap } \\
\text { Ear } \\
\text { Handgrip }\end{array}$} & \multirow{4}{*}{$170-250$} & \multirow{4}{*}{$130-180$} & \multirow{4}{*}{$150-190$} \\
\hline Herb jar & & & & & \\
\hline $\begin{array}{c}\begin{array}{c}\text { Double-ear sand } \\
\text { jar }\end{array} \\
\end{array}$ & & & & & \\
\hline Earthen jar & & & & & \\
\hline
\end{tabular}

\section{CHANGES, AESTHETIC CHARACTERISTICS AND INFLUENCING FACTORS OF MODERN BLACK SAND PRODUCTS}

\section{A. The evolution of black sand products}

The first Yingjing sand wares were used to satisfy the needs of the common people. With few decorations, they were less elegant, but had large volumes. Then people gradually began to use some patterns on the surface as decoration. In the development of more than 2000 years, the black sand ware craftsmen have learned to use elements from nature as decorative subjects to carve the surface of traditional sand ware. The integration of various techniques contributes to the black sand arts and crafts today.

Through the investigation of the local sand ware street, it is found that more and more companies dealing in Yingjing sand ware have been successfully transformed and creating many hot and exquisite tea sets, handicrafts and artworks ("Fig. 1" and "Fig. 2").
This is the new vitality of the black sand ware endowed by this era, which is also a rare opportunity for its development.

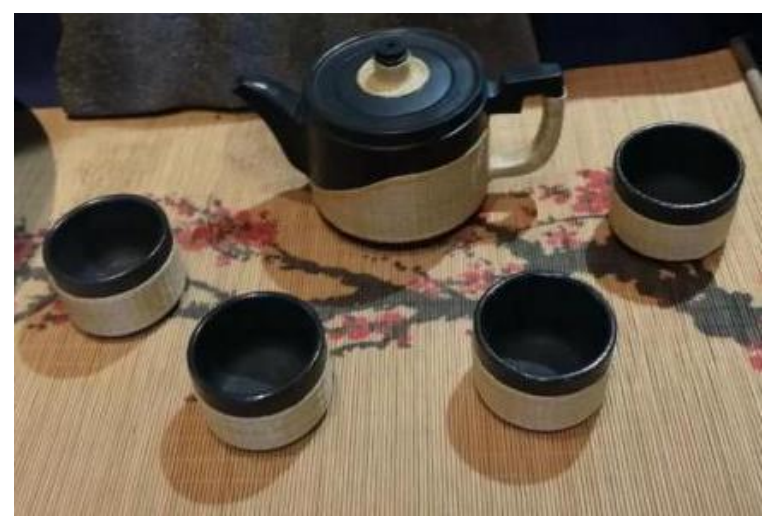

Fig. 1. A tea set with a base of porcelain-bodied bamboo ware. 


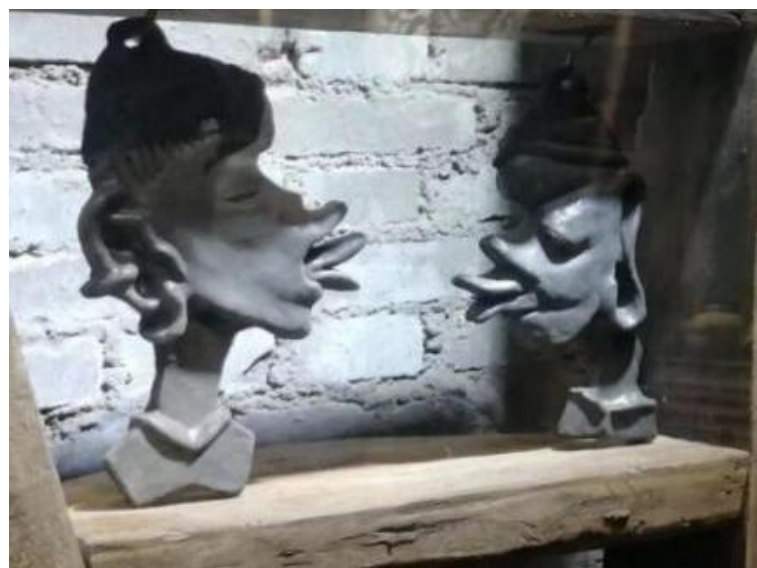

Fig. 2. Figure-themed sand ware garnitures.

\section{B. The aesthetic characteristics of modern sand ware}

In the long process of development, different countries, regions and ethnic groups often form unique aesthetic concepts or even have their value system changed under the influence of political, economic, cultural, climatic and geographical factors. After more than two thousand years of development, Yingjing sand ware has also formed a unique aesthetic characteristic due to its specific social and natural environment.

1) Historical massiveness: As an intangible cultural heritage, the art of making Yingjing sand wares reflects the social economy, human customs and living habits of Yingjing county, which is the precious wealth of human culture. The ancient pit firing technique used therein represents a pottery culture that conforms to the laws of history and natural development. It combines the traditional preform body with the modern techniques, so that it is still shining under the historical and cultural accumulation and passed on from generation to generation. It not only reflects the local social atmosphere and cultural customs of Yingjing, but also bears witness to the ethnic exchanges along the Silk Road. After so many years we finally realize the historical value of the sand ware when we look back at the scene where craftsmen worked thousands of years ago.

2) Primitive practicality: Yingjing sand ware is a type of pottery produced and developed to meet actual needs. Due to its practicability and ease of use, it conforms to the law of people's survival and development and is not eliminated by the society. Today it even brings considerable economic income to the artisans. For example, the sand pot and cutlery around the catering culture, the black sand tea set products around the tea culture, as well as the souvenirs and handicrafts oriented towards the development of Yingjing county. In a society much relying on mechanized production, the black sand products insisting on the making by hand conforms to the modern consumer's concepts of green and handmade products, creating a huge economic value. Meanwhile, as the black sand industry continues to develop, it will provide more job opportunities and promote the economic development of Yingjing county [2].

3) Value of art collection: In the long-term development process of Yingjing sand ware, part of it has gradually evolved into a work of art with appreciation value. The sand ware is the product of labor that the artisans make by hand. They devote feelings to objects with their hands, giving new life to the them and making the sand ware products show unique geographical characteristics. Each of these handmade pieces has its own characteristics, giving a comfortable visual experience with its shape, decoration and color. In recent years, Yingjing sand ware products have been well known in exhibitions both in China and abroad, and have attracted the attention of a large number of people. As a result, Yingjing sand wares are not only unpretentious everyday objects, but also works of art worth appreciating and collecting.

\section{Factors affecting the change of black sand products}

1) The reformation brought by machine: The original blanks of the modern Yingjing sand ware are mostly made of motor runners and the fast-wheel manufacturing method used before is gradually eliminated. The adoption of the machine greatly improves the work efficiency of the black sand craftsmen and makes the device more compact. Similarly, the new machine carving tools also help to improve the precision of the artisans' work, contributing to vivid decorative patterns that are delicate and beautiful.

2) Technological development: The black sand preform body made of Baishan mud proportionally mixed with dicarbon and the unique dome kiln are essential for the firing technique of Yingjing sand ware. Thanks to the reformation of the machine, the efficiency of the local mud making process has been improved rapidly, making the black sand embryo material particles finer and softer. In addition to the improved filtering ability, the surface of Yingjing sand wares is much smoother than it used to be. The finer preform body enable the sand ware to be more malleable, which makes the mass production of once extremely rare tea sets possible. In the future, there will be more and more different types of sand ware.

3) Change of the dietary habit: With the improvement of people's quality of life, the number of 
members in a single family has changed from a dozen to several, and the "food prepared in a large canteen cauldron" has long disappeared, replaced by the pursuit of small and delicate meals. As a result, the shape of the sand ware has changed and the volume becomes more suitable for a family of three.

4) Mismatching between traditional shape with the modern cooking environment: The modern gas stove is small in size and weak in bearing capacity, while the traditional shapes of pot are large and heavy, which is not convenient to use. But the unique quality of air permeability owned the Yingjing sand ware is also needed when people are cooking, so the shape change of the black sand ware is in line with modern people's usage habits.

\section{SUGGESTIONS FOR PROTECTION AND INHERITANCE OF Y INGJING SAND WARE}

The Yingjing sand ware has deposited the history and culture of more than two thousand years in Yingjing area of Ya'an, Sichuan. Its inheritance process is constantly influenced by social culture and political economy, and the black sand culture today has only come into being after going through ups and downs. As the traditional culture encounters the impact of modern industrial civilization, it is extremely urgent to inherit and protect the black sand culture of Yingjing. This not only requires the manpower and financial resources invested by the government in the black sand industry, but also, more importantly, the improvement of the inheritance mode and the expansion of communication channels. It is a necessary measure to retain the intangible cultural heritage and an important way to find the new development direction of Yingjing sand ware to explore the ways of inheritance and protection and turn challenges into opportunities.

\section{A. The government departments should play a leading role}

First of all, the government departments should timely launch beneficial support policies, explicitly include the black sand cultural industry in the key development plan, formulate corresponding industry standards for it, strengthen the industry rules and regulations, and promote the black sand cultural industry to have a good development environment. Secondly, in the performance of functions, the government should "focus more on content than form", as the establishment of the sand ware museum, Yingjing county black sand street, Yingjing county black sand expo park and other forms of protection is far from enough, and to protect the cultural connotation of the sand ware is the core of its inheritance. Finally, it is necessary to strengthen the combination of Yingjing black sand and Ya'an's culture and tourism industry. It will greatly enhance the development to form a unique black sand cultural tourism industry relying on the tourist resources in Bifeng Gorge and Mengding Mountain, which can be combined with the tea making industry [3] as frequent tea party activities usually require a large number of tea pots, tea cups and tea canisters. So the combination of the Mengding Mountain, its tea and the Yingjing sand ware can provide an external publicity platform for each other and help to better carry forward the traditional culture.

\section{B. The main body of inheritance should have a pioneer spirit}

First, it is necessary to improve the personnel training mechanism. It is important to establish sand ware training institute, strengthen the cooperation mechanism between enterprises and the school, and take it as the practical creation base of the school. And cultural exchanges and training can be actively carried out to cultivate the young generation of craftsmen, or encourage artists and experts to actively participate in the creation, so as to improve the quality of black sand art [4]. In the process of innovative design, the form, process and material should be firstly summarized and interpreted to retain the basic elements and process features of the original model to the greatest extent. In the selection of preform body for black sand ware making, the physical combination with wood, straw, metal and other materials can be explored to form a new shape or decorative style, catering to the modern aesthetic way without losing the original charm and appeal [5]. As the project leader of the renaissance and development of the Yingjing sand ware industry, Ye $\mathrm{Xiao}$ is quite accomplished in the design of the Yingjing sand ware. The value of the modified Yingjing sand ware was immediately increased, which not only increased the output, but also increased the salary of the veteran artists by several times, helping the local fight against poverty [6]. He also found a suitable online sales channel for the sand ware, providing a useful reference for local enterprises. Secondly, the enterprise should pay attention to the enhancing the ability to renew itself and further innovate the decoration and molding technology to meet the market demand. The black sand enterprises should also strengthen contact, communication and cooperation, and jointly protect and supervise the development of the black sand industry. Thirdly, the corresponding incentive and subsidy mechanism should be set up to guarantee the basic life of craftsmen and apprentices, and appropriate support and financial encouragement should be provided for young artists and college students to establish black sand enterprises. Finally, the education department can organize primary and secondary schools in Ya'an city to add black sand practice courses in the comprehensive practice activities, which will help students to have a deeper understanding of Ya'an traditional handicraft culture. 


\section{The social media should be used for publicity}

$\mathrm{TV}$, Internet, mobile phone new media and other communication channels can be used to actively publicize black sand culture, give full play to the positive side of public opinion, and create black sand as a local cultural card. Or the methods of shooting documentaries, micro films, propaganda films, etc., can be adopted to spread the black sand technology and black sand culture to the public. In addition, through exclusive interviews with managers or excellent craftsmen of black sand enterprises, the relevant deeds can be publicized and promoted to promote the formation of a good social environment and atmosphere of public opinion.

\section{CONCLUSION}

Yingjing sand ware is a good vessel used for stew. In the long process of inheritance, the shape of the vessel evolves according to the development of required functions and production techniques, and finally forms a unique modeling feature. With the continuous development of the times, people's life style is constantly updated, so it is necessary to make adjustments and innovations to the shape the sand ware. The traditional craft and materials needs not only to follow the traditional core elements, but also change with the times. If it stagnates and doesn't make innovations, then the development of Yingjing's sand ware will naturally be hindered, but too much evolution could lead to the extinction of traditional core features. How to solve this? The answer is clear. The cultural value and economic benefit of black sand should be integrated into one, and the cultural inheritance should keep pace with the times. As an economic product, as well as a carrier of culture, the shape is an important part of the transmission of the Yingjing sand ware as well as an important part of the drive for development. It is important for the young generation to realize the intrinsic value of traditional handicrafts, because many years later, they will be the backbone of society, and their actions can make traditional crafts have a bright future.

\section{References}

[1] Gou Rui, Tan Limei. Thinking on the Ying Jing Sand-Ceramic Shapes Sorting and Improvement [J]. Art \& Design, 2017 (08): 99-101. (in Chinese)

[2] Li Li. Sichuan Ya'an Balck Sand Ceramic Research and Practice [D]. Shenyang Ligong University, 2018. (in Chinese)

[3] Wang Peng. Sichuan Yingjing Clayware Research [D]. Guizhou Normal University, 2016. (in Chinese)

[4] Zhou Lan. Problems and Countermeasures of Intangible Cultural Heritage Protection in Xingjing County [J]. Strait Science and Technology and Industry, 2017(08): 103-104. (in Chinese)
[5] Li Hui. Ceramic Design Based on Cultural Needs [J]. Packaging Engineering, 2015, 36 (08): 79-82. (in Chinese)

[6] Bai Xiaoyu. Innovation is the Best Inheritance - How to Protect and Inherit the Yingjing Sand Ware of Ya'an, Sichuan [J]. Art and Literature for the Masses, 2017 (03): 59. (in Chinese) 